\title{
Sebastião Salgado: a geometrização como recurso argumentativo
}

$\frac{\text { TIEKO YAMAGUCHI MIYAZAKI }}{\text { Universidade Tuiuti do Paraná/UTP }}$ 


\section{Resumo}

A partir da discussão da natureza da fotografia como signo indicial e icônico, o artigo analisa fotos de Sebastião Salgado (Terra); mostra como, a partir de procedimentos de desreferencialização, as imagens são submetidas a processos de estilização, privilegiando traços geométricos que as reorganizam de maneira a possibilitar a emergência de novos planos de significação.

\section{Palavras-chave}

fotografia, Barthes, Salgado, desreferencialização, estilização, poética

\section{Abstract}

The essay discusses the nature of photography as indexical and iconic sign, in order to analyze Sebastião Salgado's photographs (Terra); it shows how, departing from deferential procedures, the images are submitted to a stylization process, emphasizing geometrical traits that reorganize them in a way to make it possible the emergence of new spheres of signification.

\section{Key words}

photography, deferentiality, stylization, poetics 
uito se tem insistido na natureza indicial da fotografia, contra a sua compreensão como imagem analógica, esta em virtude do imediato reconhecimento nela da figura do referente. Nela, diz Barthes

(...) o acontecimento jamais se sobrepassa para outra coisa: ela reduz sempre o corpus de que tenho necessidade ao corpo que vejo; ela éo Particular absoluto, a Contingência soberana, fosca e um tanto boba, o Tal (tal foto, e não a Foto), em suma a Tique, a Ocasião, o Encontro, o real, em sua expressão infatigável. Para designar a realidade, o budismo diz sunya, o vazio; mas melhor ainda: tathata, o fato de ser tal, de ser assim, de ser isso; tat quer dizer em sânscrito isso e levaria a pensar no gesto da criancinha que designa alguma coisa com o dedo e diz: Ta, Da, Ça! Uma fotografia sempre se encontra no extremo desse gesto; ela diz: isso é isso, é tal! Mas não diz nada mais. (1984, p.13)

A argumentação a favor de sua natureza indicial se baseia em palavras do próprio Pierce ao definir seja o índice seja o ícone, lembrando que, com relação ao primeiro, destaca a sua conexão real, física, isto é, da ordem da metonímia, com o objeto, e, com relação ao segundo, assinala que ele simplesmente denota graças a características que o objeto possui, sendo este realmente existente ou não na fotografia. A favor, pois, do índice adota-se uma perspectiva em que se invoca todo o processo físico-químico de sua produção e, nessa discussão, procura-se colocar em xeque o seu entendimento analógico, lembrando a não fidelidade da fotografia ao referente, quanto a aspectos como a coloração, a conformação tátil, sensorial etc. 
É possível aceitar a defesa do caráter metonímico quando se restringe ao processo de produção, o qual leva a situá-lo num universo mais amplo e heterogêneo, de experiências fetichizadas, em que um objeto substitui outro, ou é dado como seu substituinte, em razão do contato entre eles, muitas vezes totalmente circunstancial, mas tomado como base objetiva responsável pela sua inserção num outro mundo de valores, de práticas e ritos. A conexão física aqui é o que funda a relação: o fiel tem necessidade de tocar com os dedos a efígie santa para depois benzer-se, sem o que não lhe parece garantir a bênção desejada.

Não nos parece, por outro lado, que cabe o mesmo argumento quando se considera a incapacidade, até hoje, de a fotografia reproduzir, de forma absoluta características, traços do referente. Basta lembrar: qualquer imagem obtida pelo homem de forma natural não lhe garante o estatuto de fidedignidade absoluta: ela está sempre condicionada às limitações físico-químicas, variáveis de indivíduo a indivíduo, do aparelho ótico humano - que não é o mais perfeito entre os existentes na natureza, e das condições situacionais da percepção do objeto. Os avanços tecnológicos na área nos colocam diariamente diante da verdade da relatividade das imagens com que lidamos no dia-a-dia. Ao exemplo sempre citado da mãe, mulher primitiva, que não reconhece o filho na fotografia que the exibem, como não opor a experiência cotidiana do uso da fotografia, em suas mais modalidades, como reprodução de uma realidade em que se pretende intervir a partir do que nela se identifique como tal? Para o senso comum parece indiscutível que a constituição humana proporciona ao indivíduo o acesso a imagens de certo grau de fidelidade referencial (ainda que modalizadas por gamas de valores de diferentes axiologias), possibilitando-lhe cotidianamente atuar sobre o mundo e interagir com o próximo.

Seria sempre interessante ter presente o cuidado em não confundir real com realismo. O nexo factual, físico que possibilita a existência da fotografia faz parte do real, mas não garante o efeito de realismo. Principalmente no sentido ingênuo de fidelidade em profundidade e em pormenores. Mesmo que o reconhecimento do referente na fotografia requeira aprendizado, ela é sempre real, ain- 
da que nem sempre realista. No tocante à sua imagem não se pode aplicar a famosa frase de Magritt: ali a imagem do cachimbo sempre se referirá a um cachimbo havido, ainda que em ambos os casos, do ponto de vista da recepção, se trate de representações a partir da semelhança, garantindo, desta maneira, a natureza icônica do produto. A crença primitiva de que a imagem assim obtida significa o aprisionamento da alma do indivíduo, de certa maneira, se justifica pelas duas razões: ainda que o desconheça, o homem primitivo intui de alguma forma que a imagem resultante depende do mecanismo de fotografar, mas é o seu caráter icônico a garantia de sua certeza e de sua crença.

O fato corriqueiro, anedótico, folclórico da reação normalmente de rejeição a fotografias destinadas a documentação, exemplifica bem a diferença entre o que se pode denominar real e o que se poderia entender por realismo. A rejeição talvez proceda, de uma parte, do entendimento de que a foto é realista, ou seja, ela não esconde o que de negativo o sujeito ali vê cruamente revelado. Mas ele não pode negar que é real, ou seja, de que é a sua fotografia e não de outro: entendo desta maneira a aderência do referente de que fala Barthes.

Por outro lado, a reação do sujeito fotografado coloca em pauta o jogo de imagens de que fala Pêcheux numa relação de comunicação. Além da possibilidade de que os sujeitos tenham, de forma mais ou menos consciente e clara, qual é o ângulo em que se produziria a imagem (mais) desejada, ou qual aspecto a ser privilegiado ou a ser escamoteado, uma imagem ideal deve estar sempre à espreita, com a qual ele conta, joga, em suas relações intersubjetivas é que gostaria de ver confirmada fisicamente na materialidade da fotografia, graças à pretensa neutralidade absoluta do aparato tecnológico.

Ou ainda: é ambígua essa atração irresistível por deixar-se ou fazer-se fotografar, e mais ainda a pose intencional e declaradamente assumida. Na verdade, o que declaram essas atitudes senão a desconfiança de que a fotografia é ou não capaz de captar outros aspectos que a foto comum não expressa? Uma outra realidade, escondida, que assim se revelaria, ou que, paradoxalmente, se deixaria ver melhor quando se traveste: como se explica esse prazer de perpetuar, na fotografia e graças a ela, alguma coisa efêmera como o são as maquiagens ocasionais, a "produção" cosmética? 
Do ponto de vista da produção, não se tem um controle total sobre o resultado: a seqüência vertiginosa, quase erótica, do fotógrafo profissional de modelos, de tomadas sobre tomadas, denuncia essa fragilidade, como se se desconfiasse de que o melhor se encontre na/s diferença/s mínima/s, interpretadas como dependentes de curtíssimos intervalos temporais. Ou seja, o tempo é visto aí como o produtor-destinador avaro, controlador, dessa imagem ideal e fugidia.

Enfim, o que nos interessa nesse momento é, colocar-nos na posição de receptor, de espectador e não, portanto, de produtor, e analisar a fotografia enquanto imagem analógica, resultante de um recorte sobre o que se oferece ao olho humano, um recorte que, sem descartar o componente referencial, é fundante de uma nova realidade.

Desta perspectiva, não é gratuito o amor de Roland Barthes pelo fotograma. Diz ele:

O fotograma dá-nos o dentro do fragmento: seria preciso retomar aqui, deslocando-as, as formulações do próprio S.M.S., quando ele enuncia as novas possibilidades da montagem áudio-visual ( $n^{\circ} 218$ )...' O centro de gravidade fundamental... transfere-se para dentro do fragmento, nos elementos incluidos na própria imagem. E o centro de gravidade já não é o elemento 'entre os planos' - o choque, mas o elemento 'no plano' - a acentuação no interior do fragmento. (...) a fórmula de S.M.E. é geral, na medida em que ela estabelece um direito à disjunção sintagmática das imagens, e pede uma leitura vertical (ainda um termo de S.M.E) da articulação. (1984, p.58)

O campo cego que ele cria está próximo do da foto, e distante do da imagem cinematográfica. A narratividade que a sequiência acaba implantado aparece na foto, enquanto unidade única, como pura negatividade: a horizontalidade própria da diegese se verticaliza e se aprofunda como uma cala: ao mesmo tempo em que promove um descolamento da imagem de onde foi recortada, não lhe permitindo reinserir-se no fluxo da realidade das coisas senão às custas da perda de sua natureza específica. Num corte definitivo e sem volta, 
ao mesmo tempo a revela instalada numa outra dimensão, inacessível e mesmo incompreensível, muito próxima, emparentada ao Grande Tempo dos mitos, ao illo tempore que não se define por uma simples anterioridade ao aqui e agora, nem do espectador nem mesmo do ato fotográfico. A materialidade da película, fina, que recobre a superfície da foto, adquire a feição de um poder específico, o de imobilizar, e a imagem ganha a aura - numa dinâmica de repulsa e atração - de uma esfinge que guarda um segredo a que jamais se terá acesso: não há via de entrada, todas as portas estão trancadas, dela só se pode aproximar, mesmo que a imagem se reconheça como a do próprio espectador. Daí Barthes reconhecer esse domínio, específico da fotografia, como o da Morte.

Mais prodigiosa se torna a foto em preto-e-branco. $\mathrm{O}$ avanço tecnológico pretende alcançar aquela fidelidade e realismo a que já nos referimos: a nitide $z$ das imagens e a realidade - isto é, pertencente ao referente - das cores. Roland Barthes, porém, diz em Câmara Clara (1984 b) não gostar da cor em fotografia, pois lhe parece como algo postiço, que se agregou às coisas. Enganosa e especiosa. A palavra cor etimologicamente vem de uma raiz que significa ocultar: vem do indoeuropeu *kel, kol, kl, que se reconhecem em celare, cilium, cella, clandestino, ocultar, como lembra Ivan Lopes. Ou seja, a cor seria aquilo que esconde. Nesse sentido, o curioso é que com relação à foto, a expressão branco-e-preto é uma síntese em que os termos se refletem pelo avesso: o branco que é a reunião de todas as cores parece, à primeira vista, significar o contrário que aí estaria no preto. Nesse jogo apertado, quase em conexão física, de contrários, eles se encarregam de revelar - inclusive no sentido fotográfico - as coisas, despojando-as daquilo que as escamotearia: as cores. No branco-e-preto, no nível mais superficial da imagem-texto, a visão se desacelera porque não é dinamizada pela descontinuidade, pela variação, pela heterogeneidade. Talvez se pudesse dizer que o terceiro nível da proposição de Barthes à leitura do fotograma - o da significância - encontrasse nesse caso um de seus lugares de manifestação. Contrapondo ao sentido óbvio do segundo nível - o da significação (este "vai à minha frente: evidente, sem dúvida [...], mas de uma evidência fechada, inserida num sistema 
completo de destinação. "), Barthes propõe chamar de sentido obtuso "o outro sentido, o terceiro. Aquele que vem "a mais", como um suplemento que a minha intelecção não consegue absorver bem, ao mesmo tempo teimoso e fugidio, liso, esquivo" (1984, p.45).

De qualquer maneira, a opção pelo branco-e-preto é o ponto de partida de um movimento de estilização. A estilização compreende-se, aqui, como um processo, não de anulação, mas de neutralização de traços, de sua implicitação, graças à colocação em evidência, à priorização de outros, selecionados. Em outros termos, pode-se pensar a estilização como a textualização de um percurso inverso e posterior ao da criação do sentido. Enquanto este caminha dos níveis mais rarefeitos, conceituais, abstratos, em direção à tematização, em seguida recoberta elas opções figurativas, a estilização corresponderia a um desbaste em sentido contrário, das particularidades mais concretas: o seu efeito pode ser de desreferencialização.

A desreferencialização tem como resultado o desenraizamento do referente, arrancado de seu contexto espaciotemporal original, denotativo. É ela que possibilita, em contrapartida, graças à implicitação de semas, a instalação de outros níveis de significação, muitas vezes pouco próximas da primeira, salvando o objeto focalizado da simples contingência de que fala Barthes no trecho acima transcrito.

O livro Terra (1997), de Sebastião Salgado, particularmente, num primeiro momento exige o reconhecimento do universo referencial focalizado. É isso na verdade que a intenção manifesta na dedicatória e no prefácio dá a entender. O cotejo entre as fotografias e as legendas denuncia da mesma forma a preocupação de reinserir a fotografia em seu contexto real, sócio-histórico, devido ao reconhecimento da fluidez, da flutuação que imagem fotográfica implica. Direciona, desta maneira, a recepção delas. Ou seja, aponta para o primeiro dos três níveis de sentido que Barthes discerne no fotograma: o nível da comunicação, o nível informativo "onde se acumula todo conhecimento que me fornecem o cenário, os trajos, as personagens, as suas relações, a sua inserção numa anedota que eu conheço (ainda que vagamente)." (1984, p.43) 
No entanto, também é nesse primeiro momento da recepção que as fotos de Salgado impõe já o reconhecimento de outros níveis de sentido, sinalizados pela opção sistemática pelo branco-e-preto, em detrimento declarado do colorido. E, como ficou dito, com boa pertinência é possível ver nessas duas cores não o descarte da cor/ traço/sema, mas a implicitação dela, adensando o volume significativo dos termos explicitados.

Essa opção homologa o corte/recorte que delimita a dimensão do universo em pauta e a área em cujo interior os elementos selecionados passam a contrair relações entre eles, no âmbito de estruturas próprias.

É, pois, a partir desse recorte que as escolhas enunciativas ganham sentido. Entre elas, o enquadramento que dão aos objetos captados pelo fotógrafo o estatuto de componentes de novas estruturas que não propriamente as reconhecíveis no mundo-referente. $\mathrm{O}$ enquadramento, que nem sempre obedece à risca a conformação do espaço representado com o da representação, faz parte de estratégias enunciativas que podemos classificar como retóricas, as quais configuram no mesmo ato a imagem do sujeito observador: Obselvador não somente no sentido daquele que vê, por tratar-se de uma linguagem visual, mas no sentido daquele que escolhe como dar a ver, aspectualizando o efeito discursivo.

Na obra-corpus de Salgado, um dos efeitos dos procedimentos até aqui mencionados é a geometrização da imagem fotográfica. A geometrização se deixa apreender como que trabalhando sobre um nivel de entropia das realizações figurativas: o mundo referencial aparece aí como que imerso em uma concha de ruído, tendendo ao enfraquecimento das descontinuidades e das pertinências distintivas e, com isso, da significação. E nesse universo estilístico da geometria as figuras privilegiadas são exatamente a linha e o círculo, obtidas predominantemente graças ao posicionamento da câmera que, pelo ângulo da visão, permite que componentes, aspectos dos objetos fotografados passem a contrair novas relações, classificáveis como reiteração, paralelismo, equivalência e correspondência, chão para a emergência de sentidos metafóricos, alegóricos. O plano figurativo referencial é relegado à condição de substância que é submetida 
a uma nova ordenação formal. O mundo disfórico objeto do discurso documental, que na fotografia muitas vezes adquire uma feição dionisíaca, se reordena numa configuração apolínea.

Passemos à análise de algumas totografias!

Na construção de um ą̧ude para a retenção das águas da chuva duramte a grande seca de 1982-3 no sertão do Ceará.

os trabalhadores eram as populaçöes pobres que recebiam

como remuneração a alimentação necessária à subsistência.

Ceará, 1983.

Esta é a explicação histórica das fotografias das páginas 58-9: as consequêencias das grandes secas no Nordeste, o sofrimento humano.

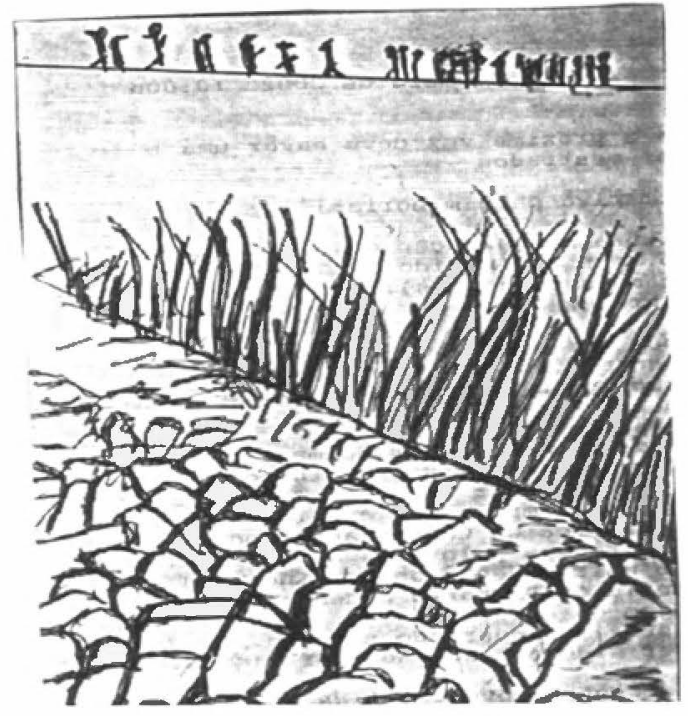

Figura 1.

Disposta verticalmente, a foto da página 58 distribui - em sua parte superior, numa faixa horizontal, fina, equivalente a dez por cento de sua dimensão, e recortada contra uma luz fraca que

1. Como a sua reprodução nâo foi autorizada, apresentamos um tipo de imagens em negativo que facilitarão acompanhar a nossa análise. 
emerge (ou imerge ?) num horizonte que não se vê - aproximadamente trinta trabalhadores na borda de um açude, caminhando da esquerda para a direita, carregando nos ombros as suas pás. Minúsculos, ao fundo e contra o fundo criado pela perspectiva, no alto da foto sublinham a linha regular, uniforme, da parede do açude seco.

Abarcando a metade da fotografia, a câmera, postada aproximadamente junto ao canto esquerdo inferior, faz avançar de baixo para o alto, em direção aos trabalhadores, um primeiro plano constituído pela visão, quase em close-up, do leito do açude. O contraste em dimensão e volume entre a terra seca, toda retalhada em torrōes completamente ressequidos, é a fila índia dos homens é onde se localiza o primeiro impacto que vem ao encontro do espectador.

O ângulo reto, assim criado pela perspectiva, forma um tríângulo cuja hipotenusa coincide com um curral de pesca feito de galhos finos, secos, desfolhados. Essa divisória, focalizada de baixo para cima mas em linha inclinada e direcionada agora da direita para a esquerda, corta a folha da fotografia ao meio fazendo resultarem, da forma retangular e vertical desta, dois triângulos retos imperfeitos. Desta maneira, toda a dimensão da foto se dinamiza graças ao movimento impresso por um jogo de vetores, que se inicia no canto esquerdo inferior, caminha sobre a borda inferior da foto, para descrever em seguida uma curva para cima. Lança-se, então, para a esquerda em linha inclinada, acompanhando o trajeto da cerca do curral de peixe a partir de sua ponta localizada no lado direito. $\mathrm{O}$ final desta, situada fora da área fotográfica, cruza no alto com o caminho percorrido pelos trabalhadores da esquerda para a direita.

Enfim, há um movimento em $\mathrm{Z}$ invertido, de forma que no canto direito superior se localize o ponto de fuga, sugerindo um horizonte que se prolonga para além do campo visual da fotografia.

A paisagem fotografada é, como já foi apontado, a de um açude seco. Esse estado atual, envolvendo a natureza e os homens, traz pressuposto todo um percurso narrativo já realizado, que pode ser sintetizado pelos termos: água - não-água - seca. Esse percurso está sublinhado - enquanto disfórico, resultante de outro, anterior, classifićável como não-disfórico pelo menos - pela presença dos restos do curral, como a proclamar: "aqui já houve peixe um dia". 
Façamos aqui uma comparação com outras fotografias. Nas páginas 54 e 68 (nas legendas "Mulher colhendo algodão" e "Reza coletiva em comunidade eclesiástica de base no Ceará, 1980") parece um cacto, como imagem barroca: numa, pela contorção dos seus galhos, numerosos, carnudos, ásperos, marcados em seus gomos, no meio da paisagem do algodoal raquítico, como que dando continuidade à figura humana do trabalhador. Noutra, pelo seu tronco pesado, lembrando um ser pré-histórico, másculo, compacto, e que, postado às costas de uma família, oferece-lhe sombra, fazendo-se símbolo encarnado de uma força poderosa. Em ambos os casos, fica a sensação de uma presença, a presença confirmada de um destinador positivo.

Já na foto do açude, alguma coisa desconforta na relação metonímica entre o grupo de trabalhadores e essa paisagem de seca, hiperbolizada por esse chão fragmentado em blocos, retalhado por sulcos profundos, flagrado pela câmara postada quase rente a ele. Um sentimento de desconforto proveniente de uma equivalência, visualmente imposta pela forma da imagem mas pouco clara em seu sentido e razão, entre a cerca seca do curral e a cerca viva dos homens caminhando. A referencialidade da função prática desses currais se esvai, ficando a impressão do caráter tosco da intervenção humana, de sua quase inutilidade. Esta parece suplantada por uma orientação de uma outra ordem que não se consegue apreender muito bem, dirigida por um anti-destinador também não identificável.

Essa mesma relação se vivência quando, numa aproximação metonímica de efeito metaforizante, se colocam de um lado os torrões de terra irregularmente arredondados, ásperos, enegrecidos, e, de outro, os três pés em close da fotografia da página contígua: pés de trabalhador braçal, metidos em chinelas havaianas, enrugados pelo barro que ali secara, com dedos e unhas reproduzindo a terra partida. Aí, a terra presa à pele humana perde totalmente qualquer conotação mítica, de regeneração, de matriz fecunda; pelo contrário, empedra aquilo que deveria permanecer humano.

Ao mesmo tempo os três pés, que terminam sinedoquicamente três pernas, colocados lado a lado sobre uma base feita de tijolos em fila, reproduzem os dois princípios geométricos citados: do esférico e do linear. Adivinha-se nos pés, que a sola gas- 
ta dos chinelos mal separa do chão, uma caminhada do esférico para o linear, como se estivessem submetidos a um processo de reificação, enquanto que nos tijolos, embora gastos pelo uso, a agressividade das bordas inicialmente lineares se mostra abrandada pela sua nova forma abaulada. Em contraste, pois, à áspera dos pés enrijecidos, há suavidade nos tijolos, sublinhada pela claridade da luz, que os humaniza e lhes confere uma força que os torna, ironicamente, capazes de suportar, sem se destruir, o que se encontra encima deles. Novamente aqui o sentimento de um destinador, natural mas antihumano, oposto, portanto, ao destinador encarnado pelo cacto.

A fotografia do açude é ambígua: em preto-e-branco, não se sabe se se trata de um amanhecer ou se trata de um entaldecer. Pelo movimento dos trabalhadores e se toma como referência a localização espacial do açude na foto, com mais razão se diria que se trata de um final de dia de trabalho. A essa leitura denotativa, uma outra se sobrepõe, em direção contrária: de uma parte o indefinível do horizonte para o qual os homens se dirigem, ironicamente situado no alto da fotografia; de outra, o bem assentado do fundo do açude seco. Colocado este junto à câmera, faz surgir um sentimento irônico que se poderia traduzir por qualquer coisa como uma chamada de atenção para o que não se pode nunca esquecer, apagar: o que está pressuposto aí a toda ação, a todo comportamento e atitude humana - a água mas ausente. Daí o baldado do trabalho humano e a sugestão de uma circularidade irônica e dramática: os homens caminham para trás da fotografia, saindo pelo canto direito superior, mas a virtualidade de seu reaparecimento no canto esquerdo inferior não está descartada.

Os princípios do esférico e do linear podem ser avaliados mais claramente nas últimas fotografias do livro: em duas páginas, focalizam os acampamentos de 2.800 famílias no sertão do Xingó, a sua invasão e a marcha para a invasão. Enquanto a penúltima fotografia abarca a linha de frente da marcha, cujo volume é dada pela largura da coluna que ela forma, a anterior faz uma tomada em plano médio de uma assembléia em momento de votação. O que prevalece, sobre a expressão dos rostos, é o movimento superativo, de baixo para cima, dos braços levantados e das mãos fechadas, que se 


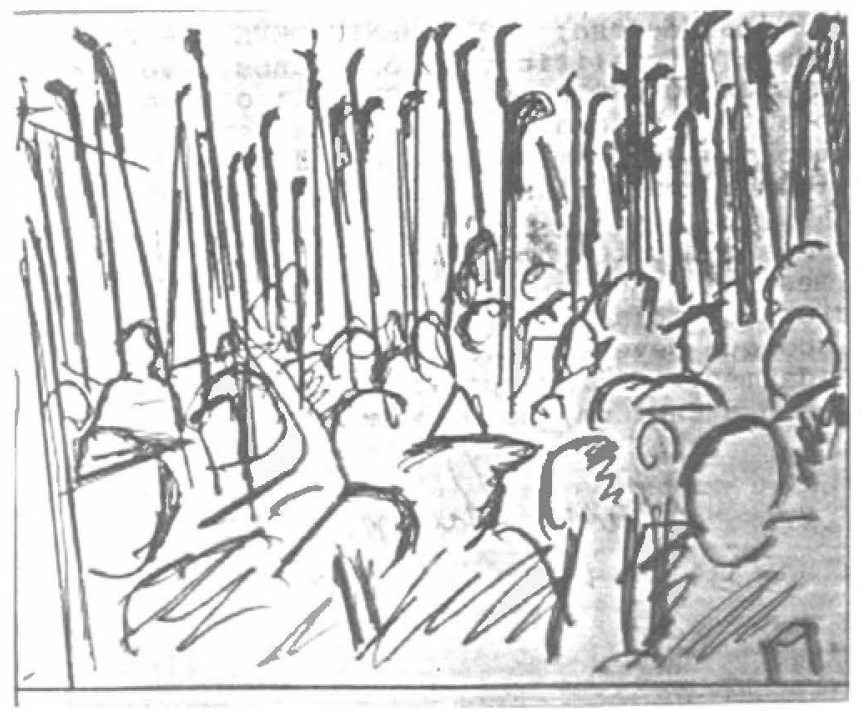

Figura 2.

repetem, se prolongam, se imitam nas foices erguidas. O traço masculino, vertical, ferino da rigidez do instrumento, no entanto, recebe um toque de flexibilidade, de bom-senso, de verdade, na superfícic plana da lâmina recortada em arco, sem que a fortaleza que a sustenta seja negada. Como se o másculino e o feminino se fundissem mas o feminino detivesse o domínio, a rédea.

Vejamos ainda a fotografia das páginas 88 e 99, de uma paisagem do lixo urbano, lançado sem qualquer cuidado junto e ao longo de uma estrada. O sentido desta, de lugar de percurso do humano, é reforçado pelas duas bicicletas e pela moto flagradas em movimento. Mas esse aporte do humano é neutralizado, toma-se impotente, insignificante nessa paisagem. Os sacos - arrendados, mais pesados - de lixo dispostos na parte inferior da fotografia, de forma visualmente caótica, são retomados ambigüamente, numa faixa horizontal no centro da foto, pela sequência de travessōes dos postes de luz. Como que se apossassem desse espaço, superior, aberto, mais claro do céu, os vultos eretos, escuros, dos postes- sem que a sua desordenação quanto ao tamanho e disposição, comprometa a idéia de continuidade - se contrapõem às paralelas inferiores traçadas pela estrada em cor mais clara, bordeada pelo lixo, em contiguiidade à 


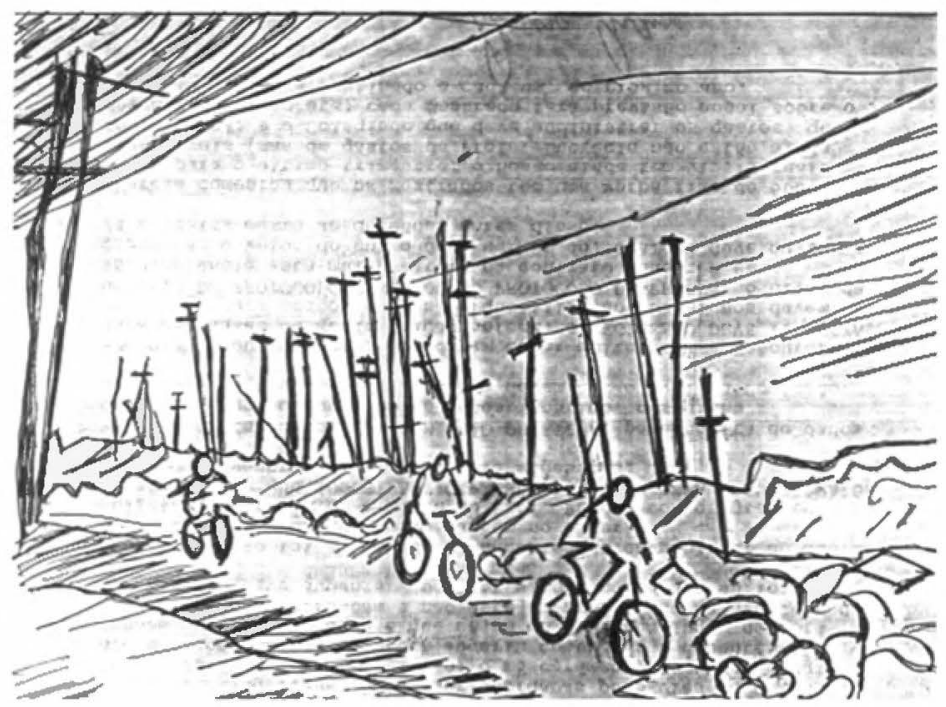

Figura 3.

faixa escura delimitada pelo campo aberto que separa a terra do claro do céu. Mas essa verticalidade parece estar ali para retomar no alto o que está cá em baixo: os volumes individuais do lixo ecoam nos segmentos descontínuos dos travessões no alto de cada poste. Sem o peso daqueles, os travessões ocupam um lugar intermediário aligeirando gradativamente as figuras, em direção à leveza do céu. Mas, ao chegar aqui, o olhar do espectador volta a ficar como que preso, tanto nesses postes verticais como na profusão horizontal de fios elétricos que, apesar do suporte dos postes, parecem soltos como verdadeiros donos do céu. Ao ultrapassarem os limites da foto, abrem espaço pelo campo cego afora.

Apesar disso, essa reiteração de linhas paralelas associada à profusão, ao excessivo das mesmas figuras e em sequiência, conduz à idéia de força, de domínio, sempre desumanizador.

Nas páginas 76/7, o tema é retomado, focalizando a ação dos catadores de lixo. Nela o espraiado do terreiro-depósito se confunde com a amplidão do horizonte como se um se prolongasse no outro, ou um se reproduzisse no outro. A mesma contigüidade se observa também com relação à população: homens e urubus convivem no mesmo espaço, dividem a partilha dos dejetos. Numa rela- 
ção de equivalência absurda, a metonímia pode levar à metáfora: vindos do céu, os pássaros negros se transformam em companheiros dos catadores de lixo, numa convivência pacífica, como indicam os urubus, em número razoável, pousados no chão. Invertendo-se a ordem dos termos, pode-se ler esses homens, carregando nas costas essas cestas-tambores, como novos urubus terrestres.

Nas fotos analisadas o mundo referencial, que compõe o nível da comunicação, uma vez debastado, é reordenado segundo estruturas desenhadas principalmente pela figura geométrica do círculo e da linha, que as mais das vezes se reiteram pelo procedimento do paralelismo. Essas disposições geométricas, como travas que sustentam a foto-texto, geram sentidos, embora presos ainda ao nível segundo da proposta barthesiana, ao nível simbólico - referencial, diegético, histórico etc., a que ele denomina da significação. O primeiro deles seria o de jogo de espelho, em que se duplica uma imagem numa estrutura elementar. Como a manifestação do termo ausente, negado, fundo sobre o qual se projeta a figura? Ou seja, em sentido contrário, a passagem da significação para a significância?

\section{Bibliografia}

BARTHES, R. 1984. O óbvio e o obtuso. Trad. Isabel Pascoal. Porto: Ed.70.

1984b. Câmara clara. Nota sobre a fotografia. Trad. J.C.Guimarães. Rio de Janeiro: Nova Fronteira, b.

DUBOIS, Ph. 1994. O ato fotográfico. Campinas: Papirus.

GRUPO M. 1993. Tratado del signo visual. Madrid: Cátedra.

MIYAZAKI, T.Y. 2001. La referencialidad despótica y la liberación retórica: lectura de fotografías de Sebastiāo Salgado. Significação- Revista brasileira de semiótica, n 16. p.79-97

2001. Pañuelos, sombreros y guirnaldas: ronda feminina em fotografias de Sebastião Salgado. Escritos. Revista del Centro de Ciências del Lenguaje.n. ${ }^{\circ 24}$. Puebla: Univ. Autónoma de Puebla, Jul.Dic. p.71-84.

SALGADO, S. 1997. Terra. S.Paulo: Cia das Letras. 